\title{
Grain Boundary Precipitation in Aged Ni-23Cr-16Mo Alloy Resolved by TEM
}

\author{
Nicoletti, E.S.M.*; Portella, P.D.**, Darwish, F.A.* and Solórzano, I.G. * \\ * DCMM, PUC-Rio, C.P. 38090 - Gávea, Rio de Janeiro, RJ, Brazil \\ ** BAM, Unter den Eichen 87, 12205 Berlin, Germany
}

Nickel base alloy 59 is a material recently designed to be highly resistant to corrosion and, therefore, to be mainly indicated for applications in chemical and petrochemical industries. The alloy contains (in weight percent): $59 \% \mathrm{Ni}, 16 \% \mathrm{Mo}, 23 \% \mathrm{Cr}$ and $1 \% \mathrm{Fe}$. While the high $\mathrm{Cr}$ content serves the purpose of guaranteeing good corrosion resistance in oxidizing atmospheres, Mo additions play the same role with respect to reducing atmospheres. ${ }^{[1]}$ Despite the expected wide applicability of the alloy in different corrosive atmospheres, corrosion pits were observed in the heat affect zone associated with welding processes. The development of corrosion pits is related to the precipitation process resulting from the heat input involved. The present study was initiated in an effort to contribute to the understanding of heat induced precipitation in alloy 59, which, eventually, could elucidate the problem of pit corrosion in heat affected zones.

Isothermal aging treatments were carried out at $700^{\circ} \mathrm{C}$ and $900^{\circ} \mathrm{C}$ and microstructural evolution was followed by maintaining the specimens at the aging temperature for 1, 10 and 100 hours. The heat treated specimens were air cooled and metallographically prepared by conventional mechanical and electrolitical methods. Microstructural characterization was carried out by scanning electron microscopy (SEM) and transmission electron microscopy (TEM), where EDS spectra were also obtained from the matrix as well as from the second phase precipitates. Thin electron foils transparent were obtained by combining dimpling, double jet polishing and ion beam milling techniques. A Jeol 2010 TEM instrument, under $200 \mathrm{~V}$ accelerating voltage, was used in the diffraction contrast and phase contrast operating conditions.

General microstructural features of the as-received alloy are presented in Fig. 1, where one can observe the presence of intergranular precipitates. Important microstructural modifications could be detected by aging the alloy at $900^{\circ} \mathrm{C}$ for 100 hours: bulk precipitation was found to take place and intergranular precipitation became significant (Fig. 2). A detail study of the precipitation morphology, structure and composition taking place at grain boundaries after aging at $900^{\circ} \mathrm{C}$ for 100 hours has been pursued. In Fig. 3a a typical grain boundary precipitate is seen as preserved after electrolitical and ion beam polishing and has been oriented near a prominent zone axis as indicated in Fig. 3c. The HRTEM image of Fig. 3b allows the observation of the atomic columns of a supperlattice that remains to be identified. The EDS spectra depicted in Figs. $3 \mathrm{~d}$ e $3 \mathrm{e}$ indicate a higher Mo and $\mathrm{Cr}$ content in these precipitates compared to that in the matrix. However, the composition of this precipitate phase is currently in process of being determined.

Being a recent developed material, scant or no knowledge exists regarding chemical composition, morphology and microstructure of precipitates that could form upon aging the alloy. The present work represents a step in the direction of contributing to that knowledge. Transmission electron microscopy is a valuable tool in that direction and it is being adopted for defined the precipitate microstructures. ${ }^{[2]}$ 
[1] Agarwal, D.C.and Herda, W.R.; The "C" Family of Ni-Cr-Mo Alloys' Partnership with Chemical Process Industry: the last 70 years; Materials and Corrosion, 48 (1997), 542-548.

[2] This study is being supported by CNPq and CAPES (Brazil).
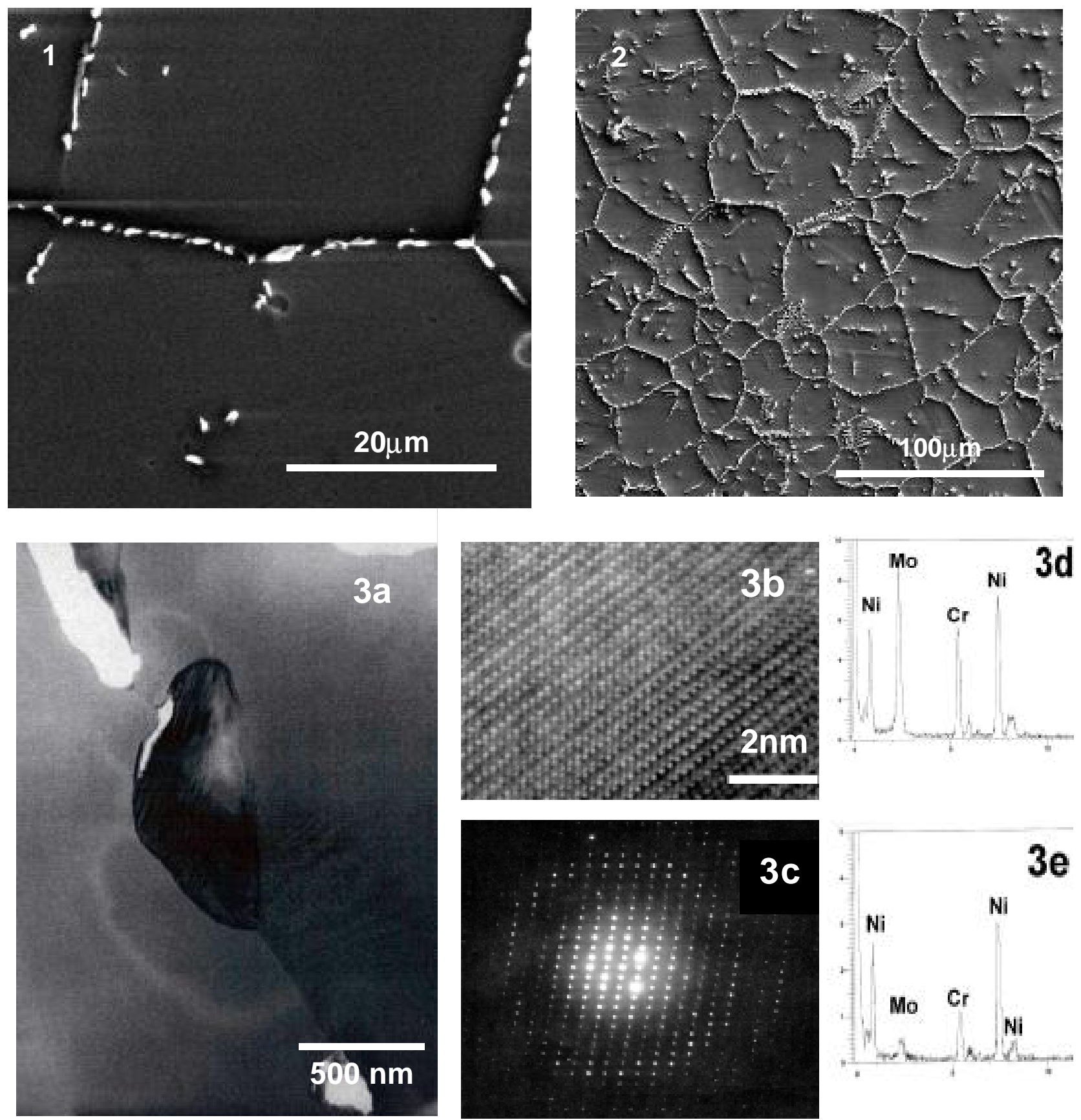

Figure 1: SEM micrograph of the as received alloy (secondary electrons).

Figure 2: SEM micrograph of the alloy aged at $900^{\circ} \mathrm{C}$ for 100 hours.

Figure 3: Grain boundary precipitate: a) bright field TEM image; b) HREM precipitate image; c) selected area diffraction pattern from the precipitate; d) EDS spectra arising from the precipitate; e) EDS spectra arising from the matrix. 